\title{
Dormancy—The Missing Links: Molecular Studies and Integration of Regulatory Plant and Environmental Interactions
}

\author{
Gregory A. Lang \\ Irrigated Agriculture Research and Extension Center, Washington State University, Prosser, WA 99350
}

\begin{abstract}
Integrating existing knowledge between seed and bud dormancy, endodormancy and cold acclimation, and research approaches to dormancy (e.g., hormones and bioregulators, molecular genetics, signal transduction, and agroclimatological modeling) is difficult. This is partly because the broad scope and expertise that is required for such integration is rarely fostered in today's technologically advanced, highly specialized research programs. Although our current concept of dormancy involves increasingly complex physiology and lacks much unifying data, a periodic attempt to integrate between and among
\end{abstract}

Dept. of Horticulture-Louisiana manuscript no. 94-17. I express appreciation to Y.H. Huang and J. Tao for assistance with the figure and to W.J. Blackmon, F.G. Dennis, N.S. Lang, G.C. Martin, and D.S. Shepard for critically reviewing the manuscript. The cost of publishing this paper was defrayed in part by the payment of page charges. Under postal regulations, this paper therefore must be hereby marked advertisement solely to indicate this fact. research areas or approaches may identify some of the links requisite for continued advancement. I will attempt to illuminate this problem and some of the potential links, such as the association of dormancy with plant stress, hormones, and biophysical properties of tissue hydration. Integrating future segments of the dormancy puzzle may depend strongly on the development of a molecular information base.

Dormancy in woody perennials involves an interrelated series of phenomena regulated by internal and external factors (Dennis, 1994; Lang, 1989; Martin, 1991; Romberger, 1963; Samish, 1954). Dormancy regulation in a specific bud, for example, may be associated initially with distant apices or subtending leaves (paradormancy, probably mediated via a hormone-type signal). Later in ontogeny, regulation may reside solely within the bud and respond to specific combinations of low and moderate temperatures or photoperiod (endodormancy, mediated via unknown biochemical transductory signals). Thus, regulation is controlled by environmental inputs and 
the developmental state of the dormant meristem and associated tissues and is manifested by a complex of poorly understood processes. Hormonal involvement, hormonal receptors, photoreceptors such as phytochrome, membrane phase changes, synthesis or activation of process-specific enzymes and those involved in general metabolism, and associations with cold- or desiccation-stress physiology complicate dormancy research.

The rapid advances in technology during the past decade may help develop new insight into the dormancy puzzle. Enzyme-linked immunoassays, molecular biology, genetic mapping and recombinant gene expression, biotechnology, nuclear magnetic resonance imaging, fourier-transformation near-infrared spectroscopy, differential scanning calorimetry, and other technological achievements have greatly increased our ability to probe certain long-standing plant science questions, including dormancy. As new experimental evidence accumulates, the potential for integrating various complementary data should increase. Successful integration, however, requires a commitment to multidisciplinary collaboration and collection of what may seem initially to be unrelated results from differing experimental systems. As networks of physiological processes are constructed, hypotheses and models will become progressively more complex, as have agroclimatological models for predicting budbreak (del Real Laborde et al., 1989; NeSmith and Bridges, 1992). The ultimate integration will occur when physiological and climatological models coalesce, becoming fully interactive and scientifically tenable.

Integration requires a universal foundation on which complex plant and environmental interactions pertinent to the dormancy puzzle can be linked. Such large-scale informational links will probably be based in molecular biology, as knowledge of common biological processes and homologous or highly conserved genetic systems increases. Horticultural scientists, who perhaps more than any other plant researchers have integrated basic and applied sciences, must apply molecular studies to dormancy complexities. Molecular studies in seed dormancy and cold acclimation, including the molecular geneticists' model plant Arabidopsis thaliana (L.) Heynh., have been underway since the early 1980s. In addition, such studies have recently been extended to include such complex horticultural plant systems as blueberry (Vaccinium corymbosum L.) and peach $[$ Prunus persica $(\mathrm{L})$. Batsch.] (Lang and Tao, 1990, 1991) and poplar (Populus deltoides Bart. ex Marsh.) (Coleman et al., 1991, 1992). The U.S. Dept. of Agriculture plant genome research program has specifically targeted a number of horticultural crops, including apple (Malus domestica Borkh.), citrus, peach, and strawberry (Fragaria $\times$ ananassa Duchesne), to map genes (or gene systems) for important traits and identify regulatory elements that control gene expression.

I will briefly compare molecular techniques with classic hormonal approaches to studying dormancy. I also will contrast prevailing paradigms with new approaches to studying dormancy. The subsequent section will review briefly a selection of molecular studies in hormone and stress physiology, followed by a discussion of molecular studies in seed and bud dormancy. The final section will discuss recent advances in nonmolecular and biophysical approaches that may broaden our ability to integrate the conceptual and informational links involved in dormancy.

\section{HOMOLOGY OF MOLECULAR AND HORMONAL RESEARCH TECHNIQUES}

The classic approach to hormone research begins by extracting plant tissues after appropriate treatments. Physiologically active substances are separated and correlative changes in relation to observed physiological events are determined. Specific chemical structures may be characterized, and whether the isolated substance is synthesized de novo or activated from an inactive form may be determined. Synthesis or activity inhibitors and in vitro synthesis to increase the amount of the substance available for study may be used. Localization of endogenous synthesis or binding in tissues or cells may be determined. Thus, a wealth of correlative hormonal data is succeeded by addition and subtraction experiments to establish more direct evidence of physiological roles in development.

In a broad sense, some molecular approaches to physiological research are similar to classic hormone research approaches- the new technology simply refocuses and expands our research options. For example, investigating the relationship between environmental cues and dormancy on a molecular level may initially focus on extracting, separating, and detecting changes in gene products (proteins and mRNAs) at specific dormancy stages or after appropriate treatments. Given sensitive detection techniques such as one- and two-dimensional polyacrylamide gel electrophoresis, alterations in the plethora of gene products will almost certainly be found. For example, Lin et al. (1991) reported that 97 proteins extracted from Pyrus seeds changed during stratification and germination. The key to such correlative research, as with hormone research, is to demonstrate a role for specific gene products produced during dormancy. This goal is realized via experimental manipulation and advanced molecular technologies, such as synthesizing radiolabeled proteins via in vitro mRNA translation, developing cDNA clones, inhibiting gene expression by antisense RNA, isolating gene promoter regions, and fusing genes to other promoters to control inducibility or quantitative changes in expression.

Compared with hormonal research, the potential of molecular research lies in uncovering many more steps in the transduction pathway from environmental signal to horticultural response. Rather than the five classes of hormones, there may be dozens of critical genes (and even more of peripheral interest) that operate during a developmental stage such as dormancy. In other words, molecular studies can link phenomena that seem to be unrelated or separate processes that seem to be a single phenomenon. For example, Liscum and Hangarter (1991) found that the influence of light on hypocotyl elongation was a function of two genetically separable processes. Far-red light exerted an influence via the phytochrome system and blue light exerted an influence via a probable flavin-like chromophore system. New research techniques allow unique discoveries, escape from the inertia of dogma, and, ultimately, new knowledge.

The potential afforded by molecular approaches is especially important if plants have redundant (possibly vestigial) control mechanisms for dormancy induction, maintenance, and release. Judging from the variety of factors that have been associated with dormancy induction or release (Erez, 1987; Lang, 1989), the concept that many regulatory mechanisms may exist, with certain factors being more prevalent and powerful (i.e., primary or obligate) than others (i.e., secondary or facultative), is increasingly attractive. For example, coincident dormancy induction factors (or inputs) might be ranked hypothetically in terms of influence: decreasing photoperiod $>$ decreasing temperature $>$ declining resource levels. Similarly, as the French school purports (Dennis, 1994), the dormant state of a bud may be influenced by existing environmental conditions and growth regulators (current inputs) and previous growing conditions that may have modulated the genetic switches that respond to resource- and receptorbased inputs. The physiological transduction of each input signal may be identifiable via changes in specific, unique gene expression. Characterizing such gene expression may help differentiate between regulators vs. modulators of various developmental stages.

\section{MOLECULAR TECHNIQUES}

\section{Molecular techniques in hormone research}

Reid (1990) and Klee and Estelle (1991) reviewed recent molecular approaches to study the physiological role of hormones in developmental processes, the biochemistry of hormone synthesis and action, and the isolation and characterization of genes involved in hormonemediated phenomena. Skriver and Mundy (1990) speculated that "different patterns of expression of (hormone)-responsive genes are due to their different hierarchies of hormonal, developmental, and spatial control elements." This suggests that, in hormonal research, target genes, not target cells, should be studied.

Skriver and Mundy (1990) summarized information on 24 abscisic acid (ABA)-responsive ( $r a b)$ genes that have been isolated from 11 species. The functions and organ specificities for most of the genes are still being deduced, although many are involved in osmotic stress responses, such as drought, salt, desiccation, cold, 
and heat tolerance. ABA-inducible genes, primarily for lea (late embryogenesis abundant) proteins, have been studied in seed systems of diverse field crops (Baker et al., 1988; Close et al., 1989; Harada et al., 1989; Litts et al., 1987; Mundy and Chua, 1988). Heino et al. (1990) used an ABA-deficient Arabidopsis mutant to demonstrate an $\mathrm{ABA}$ requirement in cold acclimation. Some regulatory genes [e.g., the $v p 1$ gene that regulates seed vivipary in maize (Zea mays L.)] can also reduce tissue sensitivity to hormones such as ABA (McCarty et al., 1989). Hetherington and Quatrano (1991) suggest that "a general role for ABA may be to prepare tissue for entry into a new and different physiological state, perhaps by resetting the direction of cellular mechanisms." The mechanism of such action may be via an effect on subordinate regulatory genes-e.g., genes coding for ABA receptors or other components of signaltransduction pathways.

Jacobsen and Close (1991) studied the gene promoters that are induced by gibberellic acid (GA) and inhibited by ABA in the multigene family for alpha-amylase. By analyzing promoter fragments, they have identified the location of GA- and ABA-responsive elements from one of the genes. Godoy et al. (1990) characterized a tomato cDNA that is inducible by ABA or salt stress but not by cold or wounding. Characterization of ABA-responsive DNA elements in gene promoter regions (Marcotte et al., 1989; Mundy et al., 1990) eventually will permit transfer of ABA responsiveness to reporter genes. This approach also may permit screening of genomic libraries with DNA probes to discover other cDNA clones encoding ABAregulated proteins.

Van der Zaal et al. (1991) found that marker-gene expression can be controlled by auxin-inducible promoters from tobacco (Nicotiana tabacum L.) and that the differential expression of auxin-inducible genes may reflect differences in minimum auxin levels required for induction (van der Zaal et al., 1987). Bacterial genes for indoleacetic acid (IAA) biosynthesis have been constructed with heat-shock promoter regions to control IAA production in transgenic tissues with heat treatment (Kares et al., 1990). The transformed tissues produced more IAA with heat and formed more roots. Controlling endogenous hormone production, relative levels, or even sensitivities by transgenic plant construction can help separate causes from effects. For example, Medford et al. (1989) and Smigocki (1991) demonstrated controlled induction of a gene for cytokinin synthesis (isopentenyl transferase) in transformed tissue by fusing it to a heat-shock promoter. Heat-treated tissue produced up to 200 -fold more zeatin and zeatin-riboside and exhibited morphological changes, such as increased axillary bud growth, consistent with cytokinin treatment. The hypothesis that apical dominance, a type of paradormancy, is controlled by a balance of IAA and cytokinin has also been addressed using transgenic plants that overproduce IAA or underproduce cytokinin. Such plants exhibit very strong apical dominance, which can be normalized by adding exogenous cytokinin. In contrast, transgenic plants that overproduce cytokinin or underproduce IAA exhibit very weak apical dominance. Smart et al. (1991) demonstrated that a cytokinin gene (tmr) coupled to a heat-shock promoter region increased levels of cytokinin and tmr mRNA in transgenic tobacco, resulting in longer side shoots.

Thus, using transgenic plants can circumvent the problems (uptake and transport) of externally applied hormones for testing hypotheses. Such research also demonstrates the potential for controlling developmental gene expression by fusing an important gene to a specific gene promoter that is inducible by an environmental or exogenously applied biochemical signal. Imagine a transgenic fruit tree that remains dormant until a grower applies a bioregulator spray to initiate growth after the probability of spring frost is minimal! Alternatively, imagine transgenic temperate fruit crops with antisense RNA (Cannon et al., 1990; Smith et al., 1988) for dormancy induction, thus facilitating tropical cultivation!

\section{Molecular links between cold acclimation and other plant stress responses}

Molecular studies of plant stress have already led to some apparent genetic links between phenomena. Christie et al. (1991) studied the cold-induced expression of a wide range of specialized genes, including stress-related (e.g., cold acclimation) and other (e.g., anthocyanin biosynthesis) genes. mRNA levels for alcohol dehydrogenase-1 (Adh1) increase rapidly with exposure to low temperatures and decrease within $24 \mathrm{~h}$ after transfer to moderate temperatures. Transcriptional activation of $A d h l$ also occurs during anaerobic stress (Rowland et al., 1989). Genes for pyruvate decarboxylase, aldolase, and sucrose synthase are expressed similarly and share a common regulatory element that responds to anaerobiosis, which Christie et al. (1991) suggest may be important for a coordinated molecular response to $\mathrm{O}_{2}$ deprivation. Cold-induced Adhl activity is distinct from that of anaerobiosisinduced $A d h l$ activity, a result suggesting that $A d h l$ genes may have different regulatory or promoter regions. If both promoters are present on the same gene, environmental cues may switch promoter activity between the two. Of interest to dormancy research is that anaerobic conditions have been postulated and experimentally associated with breaking bud dormancy (Erez et al., 1980; Samish, 1954).

Guy (1990b) has identified and attempted to sequence several coldacclimation proteins (CAP79, CAP85, CAP160) from spinach (Spinacia oleracea $\mathrm{L}$.). These proteins are present in nonacclimated tissues, but exposure to low temperatures increases their abundance, and return to moderate temperatures leads to their decline. CAP85 seems to contain sequences that have high homology to the lea class of seed proteins that are associated with desiccation tolerance and ABA or water stress induction. Guy et al. (1992) notes that the characteristics of lea class proteins also may be important for tolerance to freezing stress, which is largely a desiccation stress imposed on cells by extracellular ice formation. CAP160 and CAP85 are induced rapidly by desiccation, resulting in increased freezing tolerance. Tolerance remained even after turgidity was restored by rewatering, a result suggesting a direct molecular link between freezing tolerance, desiccation, and cold acclimation. Discovering the importance of these processes, which often coincide with endodormancy in perennial tissues, is a challenge for integrated dormancy research.

Similarly, Kurkela and Franck (1990) used Arabidopsis to identify and clone kinl, a gene that is activated by exposure to 4C temperatures, osmotic stress, and ABA. They postulated that the gene codes for a low-molecular weight $(\mathrm{mw})$, hydrophilic protein that may protect tissues at low temperatures. Lee et al. (1991) examined translatable mRNA populations in bromegrass (Bromus inermis Leyss.) cellsuspension cultures after cold acclimation at $4 \mathrm{C}$ or $\mathrm{ABA}$ treatment. Low temperatures induced fewer novel in vitro translation products than ABA, which induced 29 changes relative to controls. Three translation products were similar for cold acclimation and $\mathrm{ABA}$ treatment. This result illustrates that treatment with $\mathrm{ABA}$ (and other hormones) may activate many genes, some of which may also be induced by other factors. Only part of these responses may directly affect dormancy.

Few molecular studies have been conducted on cold acclimation in temperate-zone, woody, perennial fruit crops. Ketchie and Kammereck (1990) examined xylem proteins in cold-hardy and cold-susceptible apple trees. They found seven proteins that changed during acclimation, two of which (39 and $46 \mathrm{kD}$ ) varied differentially between the cultivars and one of which $(22 \mathrm{kD})$ was present only in the cold-hardy cultivar. Similarly, Arora et al. (1992) examined changes in peach xylem and bark polypeptides associated with increases in cold acclimation. During the dormant period (November to March), five $(14,16$, $28,33$, and $40 \mathrm{kD})$ proteins increased in the bark and one $(78 \mathrm{kD})$ increased in the xylem; all decreased from April to June. They speculated that the lower-mw polypeptides may be storage proteins and that a $100-\mathrm{kD}$ protein in bark and xylem may be associated with a plasma-membrane ATPase. Mattheis and Ketchie (1990) reported that increased plasma-membrane ATPase activity is induced by low temperatures. The specific relationships of these protein changes to cold hardiness, storage proteins, ATPase activity, and ABA levels have yet to be determined.

\section{Molecular aspects of seed dormancy}

ABA's role in dormancy induction and maintenance was equivocal a decade ago (Walton, 1980), but progress has been made in seed 
dormancy studies (Zeevaart and Creelman, 1988). Much of this progress has been the result of using molecular genetics and genetic mutants. Although the earliest work used Arabidopsis, other seed systems from herbaceous and woody plants are being used increasingly.

Karssen et al. (1983) demonstrated that seed dormancy was more closely associated with ABA content in the embryo than in maternal tissue. Koornneef et al. (1984) showed that ABA-insensitive Arabidopsis mutants also exhibited reduced seed dormancy relative to sensitive types. ABA has inhibited the transcription of some GAresponsive genes (Morris et al., 1991), a result suggesting that the ABA-GA balance may influence seed dormancy and germination. At the least, evidence that GA regulates germination (Karssen et al., 1989) and that ABA induces seed dormancy (Karssen and Lacka, 1986) is accumulating. Likewise, mutants that were insensitive to ABA produced nondormant seeds (Karssen et al., 1983). Corbineau et al. (1991) found that ABA inhibited oat (Avena sativa L.) seed germination and induced protein synthesis only when present continuously, results similar to those with ABA-inducible protein synthesis in wheat (Tritcum aestivum L.) (Reid and Walker-Simmons, 1990) and castor bean (Ricinus communis L.) (Dommes and Northcote, 1985) seeds.

Insensitivity to $\mathrm{ABA}$ in maize mutants results in the development of nondormant (viviparous) seed (McCarty et al., 1989). The gene involved in this mutation, $v p l$, controls many developmental responses, including seed germination, anthocyanin synthesis, and ABAsensitivity. The authors suggested that the $v p l$ gene product functions to potentiate multiple-signal transduction pathways and that $v p l$ is a common component of several such pathways. Eight other genes that control vivipary also affect ABA levels and carotenoid synthesis (whereas $v p l$ affects sensitivity).

Although seed dormancy induction seems to be regulated by ABA, evidence that ABA maintains seed dormancy is more tenuous. WalkerSimmons (1987) found similar ABA levels in dormant and nondormant wheat embryos, although dormant embryos were more responsive to ABA and exhibited active and prolonged synthesis of ABAinducible proteins when imbibed (Reid and Walker-Simmons, 1990). Morris et al. (1991) examined the hypothesis that specific genes, some of which are ABA-responsive, control dormancy in hydrated wheat seeds. Embryonic axes germinated readily in the absence of the caryopsis, a result indicating an imposed dormancy (analogous to paradormancy in buds) that was also manifested in the presence of exogenous ABA. ABA-responsive mRNAs from five gene families declined in nondormant hydrated seeds but were abundant in hydrated dormant embryos. Two of the gene transcripts increased during the developmental seed desiccation stage. These were characterized as very hydrophilic, a result suggesting that they may sequester water and restrict germination. Thus, Morris et al. (1991) concluded that some ABA-responsive gene expression is prolonged in imbibed, dormant seeds.

Fewer studies exist on seeds of temperate-zone tree species. Mahhou and Dennis (1993) examined polypeptide profiles in aqueous extracts from peach seed cotyledons or embryonic axes during cold (5C) and warm (20C) stratification. After 5 weeks of cold stratification, the abundance of nine cotyledon polypeptides decreased and novel, low-mw proteins appeared concomitant with a significant increase in ability to germinate. However, these changes also occurred, albeit more slowly, in seeds that were partially imbibed and unable to germinate. No profile changes were found in warm-stratified cotyledons, embryonic axes (regardless of temperature), or seeds in which dormancy was broken by $\mathrm{KGA}_{3}$. The authors concluded that the polypeptide changes were related to low-temperature responses other than dormancy alleviation, since GA broke dormancy without altering protein content. Indicative of the need for further investigation, others have found a decrease in several sodium dodecyl sulfate (SDS)soluble peach embryo (vs. cotyledon) polypeptides concomitant with breaking seed dormancy (G.A. Lang, unpublished data).

Hance and Bevington (1991) also found many changes in the relative abundance of Acer saccharum L. seed proteins during stratification. In general, chilling at $4 \mathrm{C}$ increased the capacity for protein synthesis in the embryonic axis and cotyledons within 11 days (germination occurred after 27 days of stratification). Moderate-temperature stratification (15C) induced expression of two proteins that were absent in seeds that were unstratified or stratified at 4C. Whereas GA did not alter peach seed proteins (Mahou and Dennis, 1993), Lin et al. (1991) reported that changes in pear (Pyrus serotina Rehd.) seed proteins were similar when dormancy was broken by stratification or thidiazuron (TDZ). The relationship of such changes in temperatezone tree seed proteins to gene expression and dormancy regulation remains to be determined.

\section{Molecular aspects of bud dormancy}

Nearly 30 years ago, Tuan and Bonner (1964) suggested that "if we view the problem of dormancy within the framework of molecular biology, a hypothesis immediately suggests itself, namely, that in the dormant cell, the genetic material is completely, or nearly completely, repressed." Their experimental data led them to conclude that the genome of potato (Solanum tuberosum L.) tuber buds is largely repressed during dormancy, that such repression may cause dormancy, and that breaking dormancy is associated with derepressed gene expression. Until the past few years, there has been little other molecular research conducted on bud dormancy, although the changes in various metabolic processes and temperature optima for accumulating chilling units (CUs) during dormancy suggest that an alternative hypothesis is in order. Considering the diversity and heritability of quantitative $\mathrm{CU}$ requirements for dormancy alleviation in woody perennials, the search for specific genes associated with developmental sequences of bud dormancy (i.e., induction, maintenance, release) should be made a research priority (Lang, 1989).

Molecular research on processes associated with dormancy induction in woody perennials has focused on studies with several species of poplar (e.g., P. deltoides, P. trichocarpa Hook.). Coleman et al. (1991) and Langheinrich and Tischner (1991) isolated photoperiodinducible bark storage proteins (BSPs), the accumulation of which coincides with the general time of year during which endodormancy begins. These BSPs increase in winter, disappear in summer, and are found in bark, wood, and root tissues. Although BSPs are present at low levels under long days, exposure to short days $(8 \mathrm{~h})$ increases their translatable mRNA within a week (Coleman et al., 1992). Having isolated and sequenced a full-length cDNA for a 32-kDa BSP, Coleman et al. (1992) believe it to be encoded by a family of about five genes. While the genes for such BSPs are not likely to regulate endodormancy directly, they may exist along parallel pathways with regulatory genes in the network of dormancy-associated gene expression. Precise manipulative experiments, such as transgenic plants with antisense RNA, may help determine the extent to which BSP expression can be correlated with endodormancy or cold acclimation.

Molecular research on bud dormancy release has focused on identifying biochemical markers, such as changes in polypeptides, associated with changes in endodormancy intensity during CU accumulation. Lang and Tao $(1990,1991)$ used blueberry plants in controlled-environment chambers and peach trees grown under natural conditions to examine changes in SDS-soluble polypeptide profiles. The major change in blueberry floral buds during chilling at $5 \mathrm{C}$ was an increase in polypeptides of $\approx 59$ and $65 \mathrm{kDa}$ after $1100 \mathrm{CUs}$; similar changes occur in other blueberry cultivars and species (Muthalif and Rowland, 1993). These changes coincided with the breaking of dormancy, as measured by an increase in budbreak from $18 \%$ to $96 \%$ under forcing conditions (21 days at 25C) (Lang and Tao, 1990).

During CU accumulation in peach floral buds, the most striking change was a major polypeptide of $\approx 61 \mathrm{kDa}$ (Lang and Tao, 1990), which has also been found in nectarine and plum (Prunus salicina L.) cultivars (G.A. Lang, unpublished data). The relative abundance of this polypeptide, which is present at high levels in winter and low levels in summer, decreased consistently during the final $100 \mathrm{CUs}$ accumulated for cultivars with low, moderate, and high chilling requirements, concomitant with increased budbreak at 25C (Lang and Tao, 1990,1991). A similar-mw protein has also been reported in other peach cultivars (Arora et al., 1992). The 61-kDa protein has been found in varying proportions of the total SDS-soluble protein in vegetative buds, phloem, and xylem and in much lower quantities in leaf petioles and seeds (G.A. Lang, unpublished data). 
Lang and Tao (1991) also examined the temperature dependence of changes in the $61-\mathrm{kDa}$ polypeptide relative to climatological models of CU accumulation (Richardson et al., 1974). At CU-promotive (5C), neutral (15C), and negating (24C) temperatures, changes in abundance of the 61-kDa polypeptide seemed to be specific to dormancy stage. During early endodormancy (at $30 \%$ of the CU requirement, early December), abundance increased by $25 \%$ at $5 \mathrm{C}$, was unchanged at $15 \mathrm{C}$, and decreased by $20 \%$ at $24 \mathrm{C}$, much as a climatological model might predict. However, the temperatures that promoted a decrease in abundance decreased as dormancy progressed; near the transition from late endodormancy to ecodormancy ( $90 \%$ of the CU requirement, early February), the 61-kDa polypeptide level decreased by $20 \%$ at $5 \mathrm{C}, 40 \%$ at $15 \mathrm{C}$, and nearly $60 \%$ at $24 \mathrm{C}$. This result suggests that the temperature-regulated abundance of the polypeptide is associated with dormancy stage (as indexed by CU accumulation) and is probably not related to cold deacclimation. More recent studies have demonstrated that GA and hydrogen cyanamide decrease the abundance of the 61-kDa polypeptide similarly to temperature (G.A. Lang, unpublished data). Furthermore, Arora et al. (1993) have reported crossreactivity of a similar-mw peach polypeptide to dehydrin-type protein antibodies. Further studies are needed to help identify the role of such polypeptides during peach endodormancy and identify the expression of regulatory genes that may precede these marker polypeptide changes.

Molecular inquiries into bud dormancy have just begun to address the myriad of appropriate questions. Is continuous expression of certain genes responsible for bud dormancy? Do repressed genes become active as the $\mathrm{CU}$ requirement is met? What is the balance between, and effect of temperature on, expression and repression of genes associated with dormancy as dormancy intensity changes? As endodormancy progresses, does the apparent shift in CU temperature optima indicate a network of temperature-responsive isozymes encoded by dormancy genes? How might the hierarchy of dormancy regulatory inputs be genetically engineered to benefit agriculture?

Bud dormancy in European beech (Fagus sylvatica L.) is regulated, at least late in endodormancy, by chilling temperatures and phytochrome (Fig. 1); a chilling threshold may be required to attain photoperiodic responsiveness, and chilling above the threshold reduces the time required to respond to photoperiod. If a photoperiodinducible gene promoter region is identified (Coleman et al., 1992), it might provide an experimental tool to understand dormancy initiation or maintenance under short days and serve as a potential on and off genetic switch for manipulating chimeric genes associated with dormancy or hardiness. Such photoperiodic molecular tools may eventually lead to transgenic fruit crops that begin cold acclimation soon after the fall equinox, regardless of temperature. Likewise, endodormancy could be prolonged until after the spring equinox, reducing crop damage due to spring frosts, which currently plague growers in the southeastern United States almost every other year.

\section{NONMOLECULAR AND BIOPHYSICAL TECHNIQUES}

Future research will involve gene expression and the biophysical aspects of the environment on molecular physiology. Biochemical and physical membrane restructuring usually occurs with exposure to low temperatures (Lynch, 1990; Steponkus, 1984, 1990). Membrane lipid biosynthetic enzymes are thought to be prime targets for low-temperature regulation of gene expression, as are glutathione reductase and dehydroascorbate reductase (Guy, 1990a). Some lea class proteins associated with seed maturation and desiccation tolerance (Blackman et al., 1991) may act directly by protecting intracellular components during desiccation or by affecting the tissue's water-binding characteristics. The links between temperature, alterations in membrane components, gene expression and enzyme activation, and biophysical effects on plant tissues are likely to comprise an interdependent network. These eventual links may be vital to understanding dormancy in seeds and buds.

\section{Enzymology and membrane function}

Although many enzymes have been studied with respect to dor-

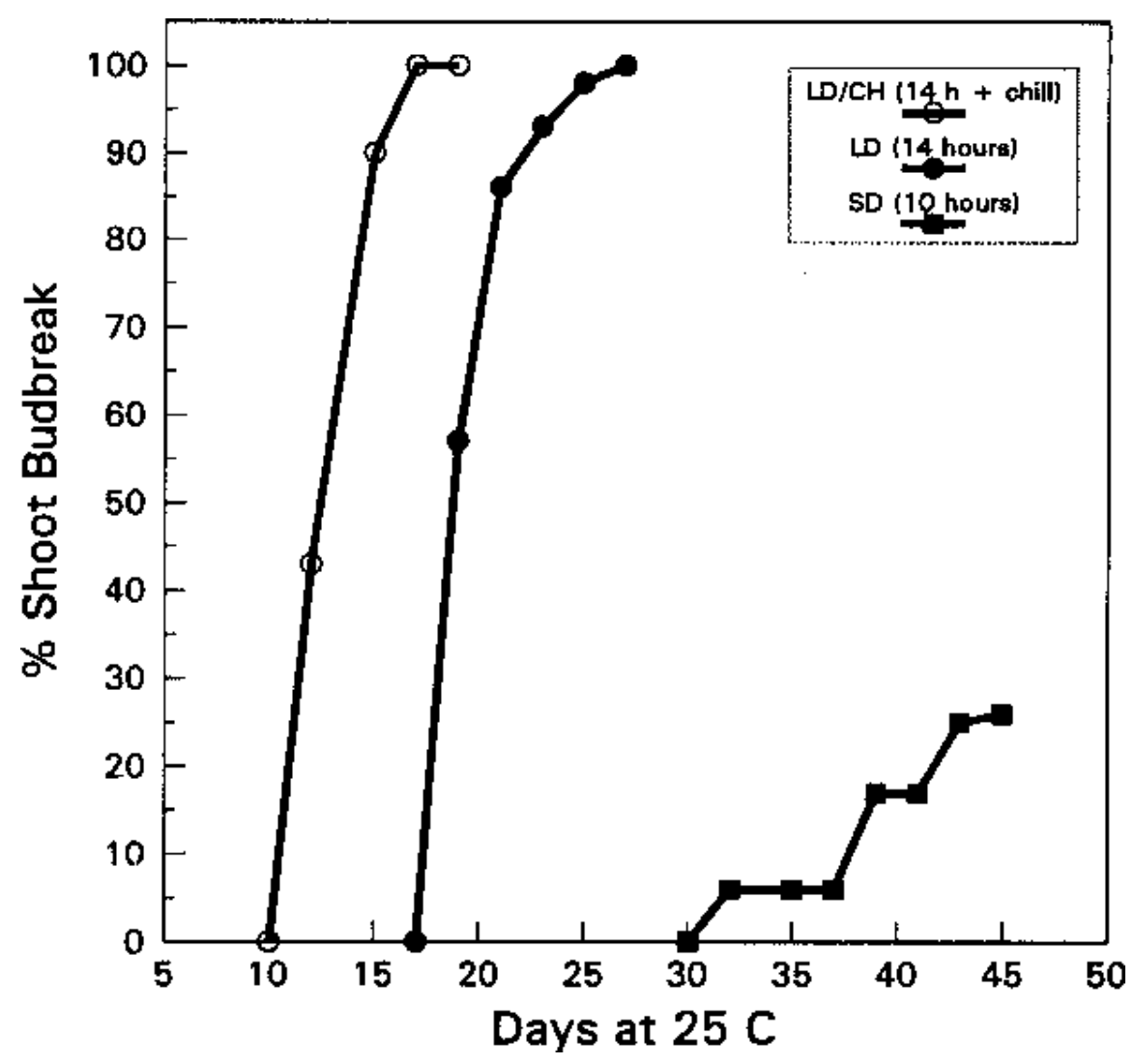

Fig. 1. Percent budbreak of excised European beech shoots at 25C under short-day (SD, 10-h) or long-day (LD, 14-h) photoperiods or long (14-h) photoperiods following $475 \mathrm{~h}$ of dark chilling at $5 \mathrm{C}(\mathrm{LD} / \mathrm{CH})$. 
mancy, little is known regarding their roles or interactions with other observed changes. Alterations in enzyme activities, isozymes, and membrane components, such as sterols and lipids, that accompany budbreak have yet to be clearly separated into mechanisms or consequences of budbreak. Although little is known about gene expression during bud dormancy, some of the many genes expressed with breaking dormancy clearly alter enzyme activity or form. Wang et al. (1991a) studied changes in activities and isozymes of catalase (CAT), peroxidase (POD), and polyphenol oxidase (PPO) concomitant with TDZ-induced budbreak of paradormant apple. CAT activity and the number of isozymes increased after treatment. POD activity was highest during dormancy, although it increased transiently after TDZ application. Although the predominant POD isozyme $(\mathrm{mw} \approx 58 \mathrm{kD})$ did not change with treatment, the second most prevalent isozyme ( $\mathrm{mw}$ $\approx 67 \mathrm{kD}$ ) decreased significantly after treatment, then increased as vegetative growth began. PPO activity was inversely related to POD activity. Nir et al. (1986) and Nir and Lavee (1992) found that POD activity increased up to $35 \%$ in endodormant grape (Vitis vinifera L.) buds after chilling or applying dormancy-breaking chemicals. With exposure to low temperatures in fall, CAT activity increased initially, then decreased to its lowest rate when the ability to break dormancy was greatest; it later increased as ambient temperatures increased. Dormancy-breaking chemicals or chilling late in dormancy decreased CAT activity by $\approx 50 \%$. Activity generally increased with temperature. In peach buds, CAT activity also decreased until the chilling-induced transition from endodormancy to ecodormancy, then it increased concomitantly with budbreak (Kaminski and Rom, 1974).

Wang and Faust (1988b) have suggested that budbreak is associated with an increased capacity to scavenge free radicals. They suggest that superoxide dismutase converts the superoxide anion $\left(\mathrm{O}_{2}{ }^{-}\right)$free radical to peroxide $\left(\mathrm{H}_{2} \mathrm{O}_{2}\right)$, which is then destroyed by CAT. Superoxide dismutase (primarily the molecular form with $\mathrm{Cu}-\mathrm{Zn}$ as the prosthetic metal) activity increased concomitant with budbreak induced by various growth regulators in paradormant apple (Wang et al., 1991d). As noted above, CAT activity also increases during budbreak in other species. Wang et al. (1991c) suggested that antioxidant systems, such as those that use ascorbate and reduced glutathione (GSH), may remove various free radicals, including $\mathrm{O}_{2}^{-}$and the hydroxyl radical $\left(\mathrm{OH}^{-}\right)$. They found that TDZ-induced apple budbreak was accompanied by an increased number of reduced compounds, such as GSH, ascorbic acid, and various thiols, and increased activities of ascorbate free-radical reductase, ascorbate peroxidase, dehydroascorbate reductase, and glutathione reductase. Siller-Cepeda et al. (1990, 1992) found that GSH levels increased in endodormant peach buds and cherry (P. mahabeb L.) seeds until the CU requirement was met (December), then decreased during January. Dormancybreaking hydrogen cyanamide treatments also induced high GSH levels. These data suggest that increased glutathione reductase activity may play an important role in chemical- and $\mathrm{CU}$-induced transitions from endodormancy to ecodormancy.

Wang et al. (1991b) measured the activities of certain enzymes involved in the glycolytic pathway-tricarboxylic acid (TCA) cycle and the pentose-phosphate cycle before and after TDZ-induced budbreak of paradormant apple buds. They observed rapid decreases in activity of two pentose-phosphate cycle enzymes (glucose-6phosphate dehydrogenase and 6-phosphate gluconate dehydrogenase) and rapid increases in the glycolytic enzymes glyceraldehyde-3phosphate dehydrogenase and pyruvate kinase and the TCA cycle enzyme isocitrate dehydrogenase. They suggested that glucose-6phosphate metabolism is shifted from the pentose-phosphate pathway to glycolysis during the breaking of paradormancy; conversely, Nir and Lavee (1992) have proposed that the breaking of endodormancy coincides with pentose-phosphate pathway activation.

Wang and Faust (1988a, 1989a, 1989b) also have documented many rapid changes in contents of sterols and galacto- and phospholipids that accompany TDZ-induced budbreak of paradormant apple buds, a result suggesting rapid membrane alterations. Liu et al. (1991) found that lipase activity increased gradually with chilling in endodormant apple buds; the increase was substantial as the CU requirement was satisfied. Increased activity was coincident with the change from bound to free water in magnetic resonance images, a result suggesting that changes in the membrane lipid composition are related to changes in tissue water status. Both processes coincided with satisfaction of the CU requirement, regardless of whether the requirement was low ( $\approx 400$ CUs, 'Anna') or high ( $\approx 2600$ CUs, 'Northern Spy'), a result suggesting a common end-of-chilling and dormancy alleviation response across genotypes.

\section{Biophysical properties of water in seeds}

Biophysical studies of cellular water are more advanced in dormant seed systems than in dormant bud tissues. During dormancy, seed water content seems to be reduced to levels that limit metabolism and prolong longevity. Vertucci (1989) and Vertucci and Roos (1990) found that specific moisture (and lipid) contents are associated with the onset of respiration, chemical reactions, and accelerated aging rates in seeds. For many species, optimum seed longevity occurred at $19 \%$ relative humidity $(\mathrm{RH})$, mitochondrial electron transport was detected at $24 \% \mathrm{RH}$, and increased rates of thermal-chemical reactions occurred at $27 \%$ RH. From seed metabolism studies, Leopold and Vertucci (1989) concluded that three hydrational levels could be delineated as seed water content (dry-weight basis) increased from $\approx 0 \%$ to $8 \%, 8 \%$ to $25 \%$, and $>25 \%$. Nonmetabolic (catabolic) enzymatic and nonenzymatic activities, including nonmitochondrial oxidative reactions only, occurred at the lower hydration levels. Integrated processes, such as mitochondrial electron transport and protein synthesis, occurred only at the third hydration level. Conversion of phytochrome from the far-red to the red light-absorbing form was thought to occur at all hydration levels. Vertucci (1990) further delineated types of seed tissue water based on motional and thermodynamic properties and related them to physiological activity, desiccation tolerance, and the proportions of water that will or will not freeze when subjected to low temperatures. Their specific relationship to structural changes of water or water-associated macromolecules has yet to be determined.

The properties of water in tissues are affected by the macromolecules present and vice versa, particularly in protein and phospholipid systems. Bound water is associated with macromolecular surfaces (interfacial water) and has different thermodynamic and motional properties than free water, the bulk cellular water in the tissue (Vertucci, 1989). The lower the tissue water content, the stronger the association of bound water with macromolecular interfaces. Leopold and Vertucci (1989) described three types of bound water: 1) tightly bound to macromolecules via ionic bonding, 2) weakly bound by condensation over hydrophilic sites on the macromolecule, and 3) bound with negligible energy as a bridge over hydrophobic sites.

Hydration level (and the three types of bound water) also corresponded to red light and temperature perception in dormancy breaking of lettuce (Lactuca sativa L.), apple, and red rice (Oryza sativa L.) seeds (Leopold and Vertucci, 1989). Desiccation increased the responsiveness of the wheat seed to gibberellin, probably by a membrane alteration that changed sensitivity. During stratification, apple seeds became sensitive to temperature at the second hydrational water level (Vertucci and Leopold, 1986). Thus, the relationship of tissue moisture content to perception of environmental cues (e.g., activation of regulatory genes) and transduction of corresponding responses (e.g., activation or synthesis of appropriate enzymes) may be critical to integrative seed dormancy studies.

\section{Biophysical properties of water in buds}

In the study of bud dormancy, the question arises whether tissue water content should be determined concomitant with other analyses to correlate with specific events during dormancy development and alleviation. Just as Leopold and Vertucci (1989) postulated that desiccation associated with seed maturation might serve as a developmental switch that can change the pattern of subsequent protein synthesis, so might the biophysical influence of bud water status be associated with dormancy-related transitions in gene expression and physiology. Biophysical studies of bud dormancy have focused on applying nuclear magnetic resonance imaging (MRI) to apple leaf buds (Faust et al., 1991; Liu et al., 1991). MRI produces characteristic 
images for water molecules that exist in various forms. Water that is strongly bound to macromolecules cannot be imaged; water that is less associated with other molecules (free water) is more readily imaged. To some extent, the degree of association can be determined by differences in the relaxation times of excited molecules.

Faust et al. (1991) reported that water in endodormant apple leaf buds cannot be imaged, suggesting a bound state. However, as the $\mathrm{CU}$ requirement is satisfied, at least part of the water dissociates from other molecules and becomes visible in bud tissue images. This conversion from bound to free water occurred at the end of CU accumulation (600 and 4000 CUs) in low-chilling 'Anna' and high-chilling 'Northern Spy', respectively. Applying TDZ to partially chilled buds resulted in a similar increase in free water within 24 h (Liu et al., 1991). Paradormant and ecodormant buds were easily imaged with MRI at any time, suggesting a different physiological dormant status based primarily on free tissue water (Faust et al., 1991). Thus, transition to endodormancy seems to involve marked changes in water properties, as suggested in the seed systems reported above. Rowland et al. (1992) reported similar changes in MRI-imaging of partially and fully chilled blueberry flower buds.

Water content in dormant buds is much higher than that in most dormant seeds. The water content in endodormant apple leaf buds increased (nonsignificantly) from $49 \%$ before chilling to $59 \%$ after chilling (Faust et al., 1991). Free water was always present in the stem, indicating that the shoot xylem has the ability to conduct free water even when none appears in the bud. Faust et al. (1991) suggested that the water in endodormant buds is primarily in the cell wall matrix, while water in ecodormant or paradormant buds is primarily intracellular. The presence of free water in the stem bark, cambial layer, and youngest xylem during the winter suggests that these tissues may never actually be endodormant.

Vertucci and Stushnoff (1992) recently used differential scanning calorimetry to study dormant vegetative apple buds. They reported that water binding was greatest when tissues were most acclimated to low temperatures. Low-temperature injury seemed to be related to damage by desiccation. These results potentially conflict with the MRI interpretations above, which suggest that MRI bound water is found only in endodormant, not paradormant or ecodormant, buds. In cold climates, maximum hardiness (implying maximum bound water) may occur after satisfying the CU requirement (i.e., ecodormancy).

In seed tissues, Leopold and Vertucci (1989) have found that thermodynamically (vs. MRI) bound water is not readily freezable. The relationship of MRI bound water to the types of bound water determined by thermodynamic and motional studies is not yet clear. Likewise, the potential relationship of any type of bound water to proteins associated with desiccation tolerance (Curry et al., 1991; Guy, 1990a; Leopold and Vertucci, 1989) has yet to be examined fully. Morris et al. (1991) have suggested that very hydrophilic proteins in dormant seeds may sequester water, resulting in extremely low water activities (Guy 1990a). A similar case might be postulated for the dehydrin-type protein (Arora et al., 1993) found in endodormant peach buds (and other tissues). The biophysical question of precisely how cold acclimation and dormancy are related still remains. However, as new experimental evidence accumulates for each phenomenon, it seems that a thorough understanding of one may not be possible without a similar understanding of the other.

\section{SUMMARY AND CONCLUSIONS}

Dormancy in plants remains an enigma, with our understanding of bud endodormancy advancing particularly slowly, a likely victim of the research difficulties inherent in plant systems that exhibit endodormancy. However, new information pertinent to dormancy has increased rapidly with advances in molecular biology and biophysical analysis technology. These advances can and should be used by physiologists and geneticists to understand important phenomena in horticultural plant systems. Complementary DNA libraries developed in Arabidopsis and other basic research-friendly systems can and should be used to probe the physiology and genomes of agriculturally important plants, particularly to examine similarities in hormone- and environmental-stress-inducible responses.
Two promising areas of molecular research into dormancy phenomena are 1) defining functions for the proteins encoded by genes that respond to dormancy-related chilling accumulation or dormancybreaking chemical treatments and 2) studying the regulatory mechanisms of such genes by signals (environmental and hormonal), i.e., signal-transduction systems. Identifying and characterizing specific genes that encode regulatory processes will improve our understanding of the physiology of dormancy and its genetic manipulation. The molecular aspects of plant response to stress or hormones, as Skriver and Mundy (1990) have noted, will have to be integrated with signaltransduction biochemistry before the picture is complete. Such signals probably involve secondary messengers, such as $\mathrm{Ca}^{2+}$ and phosphotidylinositol metabolism, and are tied to changes in gene expression via protein phosphorylation. Future research needs to focus on the interface of genetic and environmental transduction systems associated with seed and bud dormancy.

Changes in enzyme activities and isozymes during endodormancy have yet to be clearly related to mechanisms or consequences of budbreak; molecular studies may help differentiate cause and effect. The heritability of cold acclimation and endodormancy CU requirements suggests that these phenomena are clearly tied to genetics, although control is probably multigenic. Molecular studies may help separate them and lead to an understanding of how they overlap. From a mechanistic point of view, links between dormancy and cold acclimation may include biochemical components that involve gene expression or enzyme activation and biophysical components that involve membrane conformation or altered hydrational properties.

Could integrating the research areas discussed above lead to a better understanding of how chilling temperatures accumulate, ultimately acting as a transducible switch in ontogeny? How the alleviation of endodormancy is manifested more efficiently by cyclic temperature regimes (Erez and Couvillon, 1987)? How excessive chilling exposure reduces the growing-degree hours required for budbreak (NeSmith and Bridges, 1992; Scalabrelli and Couvillon, 1986)? Reconciliation between agroclimatological models and genomic, biochemical, and biophysical events will be a significant challenge and a necessary future step in advancing dormancy physiology and dormancy modeling.

\section{Literature Cited}

Arora, R., M.E. Wisniewski, and G. Davis. 1993. 60 kD polypeptide in cold acclimated bark tissue of peach is heat stable and related to dehydrin family of proteins. Plant Physiol. 102:84. (Abstr.)

Arora, R., M.E. Wisniewski, and R. Scorza. 1992. Cold acclimation in genetically related (sibling) deciduous and evergreen peach (Prunus persica [L.] Batsch). Plant Physiol. 99:1562-1568.

Baker, J.C., C. Steele, and L. Dure, III. 1988. Sequence and characterization of 6 Lea proteins and their genes from cotton. Plant Mol. Biol. 11:277-291.

Blackman, S.A., S.H. Wettlaufer, R.L. Obendorf, and A.C. Leopold. 1991. Maturation proteins associated with desiccation tolerance in soybean. Plant Physiol. 96:868-874.

Cannon, M., J. Platz, M. O’Leary, C. Sookdeo, and F. Cannon. 1990. Organspecific modulation of gene expression in transgenic plants using antisense RNA. Plant Mol. Biol. 15:39-47.

Christie, P.J., M. Hahn, and V. Walbot. 1991. Low-temperature accumulation of alcohol dehydrogenase-1 mRNA and protein activity in maize and rice seedlings. Plant Physiol. 95:699-706.

Close, T.J., A.A. Kortt, and P.M. Chandler. 1989. A cDNA-based comparison of dehydration-induced proteins (dehydrins) in barley and corn. Plant Mol. Biol. 13:95-108.

Coleman, G.D., T.H.H. Chen, S.G. Ernst, and L. Fuchigami. 1991. Photoperiod control of poplar bark storage proteins accumulation. Plant Physiol.96:686692.

Coleman, G.D., T.H.H. Chen, and L.H. Fuchigami. 1992. Complementary DNA cloning of poplar bark storage protein and control of its expression by photoperiod. Plant Physiol. 98:687-693.

Corbineau, F., A. Poljakoff-Mayber, and D. Come. 1991. Responsiveness to abscisic acid of embryos of dormant oat (Avena sativa) seeds. Involvement of ABA-inducible proteins. Physiol. Plant. 83:1-6.

Curry, J., C.G. Morris, and M.K. Walker-Simmons. 1991. Sequence analysis of a cDNA encoding a Group 3 LEA mRNA inducible by ABA or dehydration stress in wheat. Plant Mol. Biol. 16:1073-1076.

del Real Laborde, J.I., J.L. Anderson, and S.D. Seeley. 1989. A variable chill 
unit model for dormancy evaluation under subtropical conditions. HortScience 24:100. (Abstr.)

Dennis, F.G., Jr. 1994. Dormancy-What we know (and don't know). HortScience 29:1249-1255.

Dommes, J. and D.H. Northcote. 1985. The action of exogenous abscisic and gibberellic acids on gene expression in germinating castor beans. Planta 165:513-521.

Erez, A. 1987. Chemical control of budbreak. HortScience 22:1240-1243.

Erez, A. and G.A. Couvillon. 1987. Characterization of the influence of moderate temperatures on rest completion in peach. J. Amer. Soc. Hort. Sci. 112:677-680.

Erez, A., G.A. Couvillon, and S.J. Kays. 1980. The effect of oxygen concentration on the release of peach leaf buds from rest. HortScience 15:39-41.

Faust, M., D. Liu, M.M. Millard, and G.W. Stutte. 1991. Bound versus free water in dormant apple buds-A theory for endodormancy. HortScience 26:887-890.

Godoy, J.A., J.M. Pardo, and J.A. Pinto-Toro. 1990. A tomato cDNA inducible by salt stress and abscisic acid: Nucleotide sequence and expression pattern. Plant Mol. Biol. 15:695-705.

Guy, C.L. 1990a. Cold acclimation and freezing stress tolerance: Role of protein metabolism. Annu. Rev. Plant Physiol. Plant Mol. Biol. 41:187223.

Guy, C.L. 1990b. Molecular mechanisms of cold acclimation, p. 35-61. In: F. Katterman (ed.). Environmental injury to plants. Academic, San Diego.

Guy, C., D. Haskell, L. Neven, P. Klein, and C. Smelser. 1992. Hydration-stateresponsive proteins link cold and drought stress in spinach. Planta 188:265270.

Hance, B.A. and J.M. Bevington. 1991. Changes in protein synthesis in sugar maple embryos during stratification and dormancy release. Plant Physiol. 96(Suppl):63. (Abstr.)

Harada, J.J., A.J. DeLisle, C.S. Baden, and M.L. Crouch. 1989. Unusual sequence of an abscisic acid-inducible mRNA which accumulates late in Brassica napus seed development. Plant Mol. Biol. 12:395-401.

Heino, P., G. Sandeman, V. Lang, K. Nordin, and E.T. Palva. 1990. Abscisic acid deficiency prevents development of freezing tolerance in Arabidopsis thaliana (L.) Heynh. Theor. Applied Genet. 79:801-806.

Hetherington, A.M. and R.S. Quatrano. 1991. Mechanisms of action of abscisic acid at the cellular level. New Phytol. 119:9-32.

Jacobsen, J.V. and T.J. Close. 1991. Control of transient expression of a chimaeric gene by gibberellic acid and abscisic acid in protoplasts prepared from mature barley aleurone layers. Plant Mol. Biol. 16:713-724.

Kaminski, W. and R. Rom. 1974. A possible role of catalase in the rest of peach, Prunus persica Sieb. and Zucc., flower buds. J. Amer. Soc. Hort. Sci. 99:84-86.

Kares, C., E. Prinsen, H. Van Onckelen, and L. Otten. 1990. IAA synthesis and root induction with iaa genes under heat shock promoter control. Plant Mol. Biol. 15:225-236.

Karssen, C.M., D.L.C. Brinkhorst-van der Swan, A.E. Breekland, and M. Koornneef. 1983. Induction of dormancy during seed development by endogenous abscisic acid: Studies on abscisic acid deficient genotypes of Arabidopsis thaliana (L.) Heynh. Planta 157:158-165.

Karssen, C.M. and E. Lacka. 1986. A revision of the hormone balance theory of seed dormancy: Studies on gibberellin and/or abscisic acid-deficient mutants of Arabidopsis thaliana, p. 315-323. In: M. Bopp (ed.). Plant growth substances 1985. Springer-Verlag, Berlin

Karssen, C.M., S. Zagorski, J. Kepczynski, and S.P.C. Groot. 1989. Key role for gibberellins in the control of seed germination. Ann. Bot. 63:71-80.

Ketchie, D.O. and R. Kammereck. 1990. Cold hardiness related SDS-PAGE proteins of Antonovka and Golden Delicious. Proc. 23rd Intl. Hort. Congr. 23(2):4286. (Abstr.)

Klee, H. and M. Estelle. 1991. Molecular genetic approaches to plant hormone biology. Annu. Rev. Plant Physiol. Plant Mol. Biol. 42:529-551.

Koornneef, M., G. Reuling, and C.M. Karssen. 1984. The isolation and characterization of abscisic acid-insensitive mutants of Arabidopsis thaliana. Physiol. Plant. 61:377-383.

Kurkela, S. and M. Franck. 1990. Cloning and characterization of a cold- and ABA-inducible Arabidopsis gene. Plant Mol. Biol. 15:137-144.

Lang, G.A. 1989. Dormancy-Models and manipulations of environmental/ physiological regulation, p. 79-98. In: C.J. Wright (ed.). Manipulation of fruiting. Butterworths, London.

Lang, G.A. and J. Tao. 1990. Analysis of fruit bud proteins associated with plant dormancy. HortScience 25:1068

Lang, G.A. and J. Tao. 1991. Dormant peach flower bud proteins associated with chill unit accumulation or negation temperatures. HortScience 26:733. (Abstr.)

Langheinrich, U. and R. Tischner. 1991. Vegetative storage proteins in poplar: Induction and characterization of a 32- and a 36-kiloDalton polypeptide. Plant Physiol. 97:1017-1025.

Lee, S.P., T.H.H. Chen, and L.H. Fuchigami. 1991. Changes in the translatable
RNA population during abscisic acid induced freezing tolerance in bromegrass suspension culture. Plant Cell Physiol. 32:45-56.

Leopold, A.C. and C.W. Vertucci. 1989. Moisture as a regulator of physiological reaction in seeds, p. 51-68. In: P.C. Stanwood and M.B. McDonald (eds.). Seed moisture. Crop Sci. Soc. Amer., Madison, Wis. Spec. Publ. 14.

Lin, C.H., L.Y. Lee, and M.-J. Tseng. 1991. Effects of stratification and thidiazuron treatment on germination and protein synthesis of Pyrus serotina Rehd cv. Niauli. Plant Physiol. 96(Suppl):62. (Abstr.)

Liscum, E. and R.P Hangarter. 1991. Arabidopsis mutants lacking blue lightdependent inhibition of hypocotyl elongation. Plant Cell 3:685-694.

Litts, J.C., G.W. Colwell, R.L. Chakerian, and R.S. Quatrano. 1987. The nucleotide sequence of a cDNA clone encoding the wheat Em protein. Nucleic Acids Res. 15:3607-3618.

Liu, D., H.A. Norman, G.W. Stutte, and M. Faust. 1991. Lipase activity during endodormancy in leaf buds of apple. J. Amer. Soc. Hort. Sci. 116:689-692.

Lynch, D. 1990. Chilling injury in plants: The relevance of membrane lipids, p. 17-34. In: F. Katterman (ed.). Environmental injury to plants. Academic, San Diego.

Mahhou, A. and F.G. Dennis, Jr. 1994. Protein changes in peach seeds during chilling are not associated with breaking dormancy. J. Amer. Soc. Hort. Sci. 119:131-135.

Marcotte, Jr., W.R., S.H. Russell, and R.S. Quatrano. 1989. Abscisic acidresponsive sequences from the Em gene of wheat. Plant Cell 1:969-976.

Martin, G.C. 1991. Bud dormancy in deciduous fruit trees, p. 183-225. In: F.C. Steward (ed.). Plant physiology: A treatise. vol. 10. Growth and development. Academic, New York.

Mattheis, J. and D.O. Ketchie. 1990. Changes in parameters of the plasmalemma ATPase during cold acclimation of apple (Malus domestica) tree bark tissue. Physiol. Plant. 78:616-622.

McCarty, D.R., C.B. Carson, P.S. Stinard, and D.S. Robertson. 1989. Molecular analysis of viviparous-1: An abscisic acid-insensitive mutant of maize. Plant Cell 1:523-532.

Medford, J.I., R. Horgan, Z. El-Sawi, and H.J. Klee. 1989. Alterations of endogenous cytokinins in transgenic plants using a chimeric isopentenyl transferase gene. Plant Cell 1:403-413.

Morris, C.F., R.J. Anderberg, P.J. Goldmark, and M.K. Walker-Simmons. 1991. Molecular cloning and expression of abscisic-acid responsive genes in embryos of dormant wheat seeds. Plant Physiol. 95:814-821.

Mundy, J. and N.-H. Chua. 1988. Abscisic acid and water stress induce the expression of a novel rice gene. European Mol. Biol. Organization J. 7:2279-2286.

Mundy, J., K. Yamaguchi-Shinozaki, and N.-H. Chua. 1990. Nuclear proteins bind conserved elements in the abscisic acid-responsive promoter of a rice $r a b$ gene. Proc. Natl. Acad. Sci. USA 87:406-410.

Muthalif, M.M. and L.J. Rowland. 1993. Characterization of chilling-regulated proteins in floral buds of blueberry. HortScience 28:520. (Abstr.)

NeSmith, D.S. and D.C. Bridges. 1992. Modelling chilling influences on cumulative flowering: A case study using 'Tifblue' rabbiteye blueberry. J. Amer. Soc. Hort. Sci. 117:698-702.

Nir, G. and S. Lavee. 1992. Metabolic changes during cyanimide induced dormancy release in grapevines. Acta Hort. 329:271-274.

Nir, G., Y. Shulman, L. Fanberstein, and S. Lavee. 1986. Changes in the activity of catalase $(\mathrm{EC} 1.11,1.6)$ in relation to the dormancy of grapevine (Vitis vinifera L.) buds. Plant Physiol. 81:1140-1142.

Reid, J.B. 1990. Phytohormone mutants in plant research. J. Plant Growth Regulat. 9:97-111

Reid, J.L. and M. Walker-Simmons. 1990. Synthesis of abscisic acid-responsive, heat-stable proteins in embryonic axes of dormant wheat grain. Plant Physiol. 93:662-667.

Richardson, E.A., S.D. Seeley, and D.R. Walker. 1974. A model for estimating the completion of rest for 'Redhaven' and 'Elberta' peach trees. HortScience 9:331-333.

Romberger, J.A. 1963. Meristems, growth, and development in woody plants. U.S. Dept. of Agr. Tech. Bul. 1293.

Rowland, L.J., Y.-C. Chen, and P.S. Chourey. 1989. Anaerobic treatment alters the cell specific expression of Adh-1,Sh, and Sus genes in roots of maize seedlings. Mol. Gen. Genet. 218:33-40.

Rowland, L.J., D. Liu, M.M. Millard, and M.J. Line. 1992. Magnetic resonance imaging of water in flower buds of blueberry. HortScience 27:339-341.

Samish, R.M. 1954. Dormancy in woody plants. Annu. Rev. Plant Physiol. 5:183-204.

Scalabrelli, G. and G.A. Couvillon. 1986. The effect of temperature and bud type on rest completion and the $\mathrm{GDH}^{\circ} \mathrm{C}$ requirement for budbreak in 'Redhaven' peach. J. Amer. Soc. Hort. Sci. 111:537-540.

Siller-Cepeda, J.H., L.H. Fuchigami, and T.H.H. Chen. 1990. Changes in glutathione and catalase activity associated with breaking of dormancy in cherry seeds. HortScience 25:1133. (Abstr.)

Siller-Cepeda, J.H., L.H. Fuchigami, and T.H.H. Chen. 1992. Glutathione 
content in peach buds in relation to development and release of rest. Plant Cell Physiol. 33:867-872.

Skriver, K. and J. Mundy. 1990. Gene expression in response to abscisic acid and osmotic stress. Plant Cell 2:503-512.

Smart, C.M., S.R. Scofield, M.W. Bevan, and T.A. Dyer. 1991. Delayed leaf senescence in tobacco plants transformed with $t m r$, a gene for cytokinin production in Agrobacterium. Plant Cell 3:647-656.

Smigocki, A.C. 1991. Cytokinin content and tissue distribution in plants transformed by a reconstructed isopentenyl transferase gene. Plant Mol. Biol. 16:105-115.

Smith, C.J.S., C.F. Watson, J. Ray, C.R. Bird, P.C. Morris, W. Schuch, and D. Grierson. 1988. Antisense RNA inhibition of polygalacturonase gene expression in transgenic tomatoes. Nature 334:724-726.

Steponkus, P.L. 1984. Role of the plasma membrane in freezing injury and cold acclimation. Annu. Rev. Plant Physiol. 35:543-584.

Steponkus, P.L. 1990. Cold acclimation and freezing injury from a perspective of the plasma membrane, p. 1-16. In: F. Katterman (ed.). Environmental injury to plants. Academic, San Diego.

Tuan, D.Y.H. and J. Bonner. 1964. Dormancy associated with repression of genetic activity. Plant Physiol. 39:768-772.

van der Zaal, E.J., F.N.J. Droog, C.J.M. Boot, L.A.M. Hensgens, J.H.C. Hoge, R.A. Schilperoort, and K.R. Libbenga. 1991. Promoters of auxin-induced genes from tobacco can lead to auxin-inducible and root tip-specific expression. Plant Mol. Biol. 16:983-998.

van der Zaal, E.J., J. Memelink, A.M. Mennes, A. Quint, and K.R. Libbenga. 1987. Auxin-induced mRNA species in tobacco cell cultures. Plant Mol. Biol. 10:145-157.

Vertucci, C.W. 1989. The effects of low water contents on physiological activities of seeds. Physiol. Plant. 77:172-176.

Vertucci, C.W. 1990. Calorimetric studies of the state of water in seed tissues. Biophysical J. 58:1463-1471.

Vertucci, C.W. and A.C. Leopold. 1986. Physiological activities associated with hydration level in seeds, p. 35-49. In: A.C. Leopold (ed.). Membranes, metabolism and dry organisms. Cornell Univ. Press, Ithaca, N.Y.
Vertucci, C.W. and E.E. Roos. 1990. Theoretical basis of protocols for seed storage. Plant Physiol. 94:1019-1023.

Vertucci, C.W. and C. Stushnoff. 1992. The state of water in acclimating vegetative buds from Malus and Amelamchier and its relationship to winter hardiness. Physiol. Plant. 86:503-511.

Walker-Simmons, M.K. 1987. ABA levels and sensitivity in developing wheat embryos of sprouting resistant and susceptible cultivars. Plant Physiol. 84:61-66.

Walton, D.C. 1980. Biochemistry and physiology of abscisic acid. Annu. Rev. Plant Physiol. 31:453-489.

Wang, S.Y. and M. Faust. 1988a. Changes of fatty acids and sterols in apple buds during bud break induced by a plant bioregulator, thidiazuron. Physiol. Plant. 72:115-120.

Wang, S.Y. and M. Faust. 1988b. Metabolic activities during dormancy and blooming of deciduous fruit trees. Israel J. Bot. 37:227-243.

Wang, S.Y. and M. Faust. 1989a. Nitroguanidines induce bud break and change sterol content in apple. J. Plant Growth Regulat. 8:143-151.

Wang, S.Y. and M. Faust. 1989b. Changes in membrane polar lipids associated with bud break in apple induced by nitroguanidines. J. Plant Growth Regulat. 8:153-161.

Wang, S.Y., H.J. Jiao, and M. Faust. 1991a. Changes in the activities of catalase, peroxidase, and polyphenol oxidase in apple buds during bud break induced by thidiazuron. J. Plant Growth Regulat. 10:33-39.

Wang, S.Y., H.J. Jiao, and M. Faust. 1991b. Changes in metabolic enzyme activities during thidiazuron-induced lateral budbreak of apple. HortScience 26:171-173.

Wang, S.Y., H.J. Jiao, and M. Faust. 1991c. Changes in ascorbate, glutathione, and related enzyme activities during thidiazuron-induced bud break of apple. Physiol. Plant. 82:231-236.

Wang, S.Y., H.J. Jiao, and M. Faust. 1991d. Changes in superoxide dismutase activity during thidiazuron-induced lateral bud break of apple. HortScience 26:1202-1204

Zeevaart, J.A.D. and R.A. Creelman. 1988. Metabolism and physiology of abscisic acid. Annu. Rev. Plant Physiol. Plant Mol. Biol. 39:439-473. 